\title{
Ventral Neural Progenitors Switch toward an Oligodendroglial Fate in Response to Increased Sonic Hedgehog (Shh) Activity: Involvement of Sulfatase 1 in Modulating Shh Signaling in the Ventral Spinal Cord
}

\author{
Cathy Danesin, ${ }^{1}$ Eric Agius, ${ }^{1}$ Nathalie Escalas, ${ }^{1}$ Xingbin $\mathrm{Ai},{ }^{2}$ Charles Emerson, ${ }^{2}$ Philippe Cochard, ${ }^{1}$ and Cathy Soula ${ }^{1}$ \\ ${ }^{1}$ Centre de Biologie du Développement, Unité Mixte de Recherche 5547, Centre National de la Recherche Scientifique/Université Paul Sabatier, Université \\ Paul Sabatier, 31062 Toulouse Cedex, France, and ${ }^{2}$ Boston Biomedical Research Institute, Watertown, Massachusetts 02472
}

\begin{abstract}
In the embryonic chick ventral spinal cord, the initial emergence of oligodendrocytes is a relatively late event that depends on prolonged Sonic hedgehog (Shh) signaling. In this report, we show that specification of oligodendrocyte precursors (OLPs) from ventral Nkx2.2expressing neural progenitors occurs precisely when these progenitors stop generating neurons, indicating that the mechanism of the neuronal/oligodendroglial switch is a common feature of ventral OLP specification. We further show that an experimental early increase in the concentration of Shh is sufficient to induce premature specification of OLPs at the expense of neuronal genesis indicating that the relative doses of Shh received by ventral progenitors determine whether they become neurons or glia. Accordingly, we observe that the Shh protein accumulates at the apical surface of Nkx2.2-expressing cells just before OLP specification, providing direct evidence that these cells are subjected to a higher concentration of the morphogen when they switch to an oligodendroglial fate. Finally, we show that this abrupt change in Shh distribution is most likely attributable to the timely activity of Sulfatase 1 (Sulf1), a secreted enzym that modulates the sulfation state of heparan sulfate proteoglycans. Sulf1 is expressed in the ventral neuroepithelium just before OLP specification, and we show that its experimental overexpression leads to apical concentration of Shh on neuroepithelial cells, a decisive event for the switch of ventral neural progenitors toward an oligodendroglial fate.
\end{abstract}

Key words: Sonic hedgehog; neural specification; oligodendrocyte precursors; sulfatase 1; neuroglial switch; spinal cord

\section{Introduction}

The generation of various subtypes of neurons and glial cells at the right time and place is fundamental for the proper development and function of the vertebrate CNS. Although the role of spatial patterning factors in generating neural cell diversity in brain and spinal cord has been well characterized, the mechanisms underlying the sequential production of neuronal and glial precursors from neural progenitors remain poorly understood. In the ventral spinal cord, the graded activity of the morphogen

\footnotetext{
Received Dec. 1, 2005; revised March 20, 2006; accepted March 22, 2006.

This work was supported by Centre National de la Recherche Scientifique and MENRT and by grants from Association pour la Recherche sur le Cancer, Association pour la Recherche de la Sclérose en Plaque, Association européenne contre les leucodystrophies, and European economic community (QLG3-CT-2000-01556). We thank our friends and colleagues in the Centre de Biologie du Développement for help, encouragement, and advice, especially Alain Vincent and Julian Smith for insightful comments on this manuscript. We thank our colleagues who generously provided us with valuable reagents: R. Bansal and J.-L. Thomas for 04 antibody, H. Takebayashi for anti-0lig2 antibody, C. Tabin for patched and Shh CDNA, D. Anderson for olig2 and ngn2, J. Michaud for sim1, M. Ballivet for neuroM, and A. Vincent for ebf2. We acknowledge the Developmental Studies Hybridoma Bank [developed under the auspices of the National Institute of Child Health and Human Development and maintained by the Department of Biological Sciences, University of lowa (lowa City, IA)] for supplying monoclonal antibodies and Biogen for providing the human Shh recombinant protein.

Correspondence should be addressed to Cathy Soula, Centre de Biologie du Développement, Unité Mixte de Recherche 5547, Centre National de la Recherche Scientifique/Université Paul Sabatier, Université Paul Sabatier, BâtIVR3, 118 Route de Narbonne, 31062 Toulouse Cedex, France. E-mail: soula@cict.fr.

DOI:10.1523/JNEUROSCI.0715-06.2006

Copyright $\odot 2006$ Society for Neuroscience $\quad$ 0270-6474/06/265037-12\$15.00/0
}

Sonic hedgehog (Shh), produced by notochord and floor plate cells, has been shown to be essential for the generation of five distinct progenitor domains, each characterized by a precise combinatorial expression of transcription factors that constitutes a molecular code for the specification of the various ventral neuronal subtypes (Briscoe et al., 2000; Jessell, 2000; Briscoe and Ericson, 2001; Marquardt and Pfaff, 2001). The observation that the first wave of oligodendrocytes (OLs), the myelinating cells of the vertebrate CNS, also emerge from restricted sets of progenitor cells located in a discrete region of the ventral neuroepithelium rather than from diffuse location constitutes the initial indication that the domain organization of the neuroepithelium may also regulate gliogenesis (Miller, 2002; Rowitch, 2004). One well described source of oligodendrocyte precursors (OLPs) in the ventral neuroepithelium is the ventral motor neuron progenitor (pMN) domain, composed of Olig-expressing neural progenitors, which generate motoneurons (MNs) during early development of the neural tube (Lu et al., 2000, 2002; Zhou et al., 2000, 2001; Takebayashi et al., 2002; Zhou and Anderson, 2002). Birthdating studies have clearly shown that MNs and OLs are not produced simultaneously from these progenitors, but that specification of these lineages occurs in two successive waves, with MNs produced first (Richardson et al., 2000; Soula et al., 2001; Rowitch et al., 2002). 
As is the case for MNs, the emergence of ventral spinal cord OLPs was shown to be mostly dependent on induction involving local activity of Shh produced by floor plate cells (Poncet et al., 1996; Pringle et al., 1996; Soula et al., 2001; Agius et al., 2004; Park et al., 2004). The fact that Shh signaling is required to specify OLP, at a time long after dorsoventral neuronal patterning is completed (Orentas et al., 1999; Soula et al., 2001; Agius et al., 2004; Park et al., 2004), raises the question of how a single signaling molecule can confer chronologically distinct identities on the same set of ventral neural progenitors. Here, we show that artificially raising the concentration of Shh in the early neural tube is sufficient to make the neuronal/oligodendroglial (N/OL) switch occur earlier in the ventral spinal cord. We also provide evidence that, during normal development, Shh protein accumulates at the surface of ventral neural progenitors as they stop generating neurons and switch to an OL fate. We further show that this accumulation is attributable to the activity of Sulfatase 1 (Sulf1), an enzyme that modulates the sulfation state of heparan sulfate proteoglycans (HSPGs), and suggest that this is a decisive step in the N/OL transition.

\section{Materials and Methods}

Fertilized White Leghorn chicken eggs, obtained from a commercial source, were incubated at $38^{\circ} \mathrm{C}$ until they reached the appropriate stages (Hamburger and Hamilton, 1992).

\section{Isolation and culture of neural tissues}

Cervicobrachial spinal cords were manually dissected from chick embryos at various stages of development. Flat-mount preparations of spinal cord explants were cultivated using an organotypic culture system described previously (Mekki-Dauriac et al., 2002; Agius et al., 2004). Briefly, embryonic day 1.5 (E1.5) neural tube or E4 spinal cord explants, isolated from surrounding tissues, were opened along the dorsal midline and flattened on a nitrocellulose membrane (Sartorius, Goettingen, Germany) with the neuroepithelial precursors up. The explants were then grown as organotypic cultures in DMEM (Invitrogen, San Diego, CA) supplemented with 10\% FCS (Sigma, St. Louis, MO). When indicated, the recombinant N-terminal fragment of the human-Shh protein (Biogen, Cambridge, MA) was added to the culture medium at the time of plating, to a final concentration varying from 25 to $100 \mathrm{~nm}$. Preparation and cultures of ventral neuroepithelial explants were performed as described previously (Soula et al., 2001). Briefly, neuroepithelial explants were dissected from transverse vibratome sections of isolated cervicobrachial spinal cords and plated on collagen gel-coated $12 \mathrm{~mm}$ plastic coverslips in $14 \mathrm{~mm}$ wells (Nunc, Naperville, IL). Cultures were fixed at appropriate intervals in $3.7 \%$ formaldehyde/PBS and processed for immunostaining or in situ hybridization.

\section{Electroporation}

Expression constructs were cloned into either the pIRES2-EGFP (Clontech, Cambridge, UK) for Shh cDNA containing the entire coding region (a gift from Dr. C. Tabin, Harvard Medical School, Boston, MA) or the pAG vector for quail Sulf1 (Ai et al., 2003).

In ovo electroporation in E1.5 neural tube. Electroporation experiments were performed as described previously (Itasaki et al., 1999). Briefly, the Shh construct was injected at $0.5 \mu \mathrm{g} / \mu \mathrm{l}$ in the rostral neural tube using a glass pipette. Electrodes (Nepa Gene Corporation, Chiba, Japan) were positioned on each side of the neural tube and four pulses of $20 \mathrm{~V}$ (Intracel, TSS10) were applied to trigger unilateral entry of the DNA into the neural tube, the nontransfected half constituting an internal control.

Electroporation of E4 spinal cord. E4 spinal cord electroporation was performed ex ovo (see Fig. 6A). Qsulf1 expression vector was used at 5 $\mu \mathrm{g} / \mu \mathrm{l}$ in combination with pEGFP $(2 \mu \mathrm{g} / \mu \mathrm{l}$; Clontech). Controls were performed with pEGFP vector alone. Embryos were harvested and isolated in a Petri dish with the dorsal side up, and DNA solution was injected into the lumen of the spinal cord as described above. Electrodes were then positioned on each side of the cervicobrachial region of the spinal cord, the positive electrode being placed more ventrally than the negative one, allowing satisfactory electroporation of ventral regions. Ten pulses of $25 \mathrm{~V}$ were applied and the spinal cord was then dissected and grown in organotypic culture.

\section{Grafts of Shh-producing cells}

QT6 Shh-producing fibroblasts were prepared as described previously (Poncet et al., 1996; Pourquié et al., 1996). QT6-Shh cell aggregates were implanted in ovo at E1.5 at the trunk level into a slit made between neural tube and somites over a distance of one to four somites. The aggregates were placed as ventrally as possible to localize the ectopic source of Shh to the ventral region of the neural tube. At E4-E4.5, a large region of the embryo surrounding the manipulated area was dissected and fixed.

\section{Staining procedures}

Tissue preparation. Embryos or flat-mounted explants were fixed in $3.7 \%$ formaldehyde in PBS, either for $4 \mathrm{~h}$ at $4^{\circ} \mathrm{C}$ and processed for immunohistochemistry, or overnight at $4^{\circ} \mathrm{C}$ and processed for in situ hybridization. The tissues were then sectioned at $60-80 \mathrm{~mm}$ on a vibratome (Leica, Nussloch, Germany) before being processed. Ventral neuroepithelial explants were fixed overnight in 3.7\% formaldehyde in PBS. For detection of Shh on spinal cord sections, we used the protocol described by Gritli-Linde et al., (2001) that allows preservation of extracellular matrix molecules. Specimens were fixed overnight in cold 95\% ethanol and $1 \%$ acetic acid (Sainte Marie's solution), and then washed in $95 \%$ ethanol.

Immunostaining. OL precursors were identified using the mouse monoclonal $\mathrm{O} 4$ antibody $(\mathrm{O} 4 \mathrm{mAb})$, which recognizes sulfatides at the surface of immature and differentiated OLs (Sommer and Schachner, 1981; Bansal et al., 1989; Ono et al., 1995; Soula et al., 2001). Culture supernatant obtained from $\mathrm{O} 4$ hybridoma cells, a gift from Dr. R. Bansal (University of Connecticut Medical School, Farmington, CT), was used diluted 1:2. The anti-Olig2 antiserum (Takebayashi et al., 2000) was used at 1:2000 dilution. The monoclonal antibody directed against the neuronal class III-tubulin (TUJ1; Covance, Princeton, NJ) was used at 1:2000. All the following monoclonal antibodies (culture supernatants) were obtained from Developmental Studies Hybridoma Bank (Iowa City, IA): motor neuron restricted 2 (MNR2) used at 1:8 (81.5C10) (Tanabe et al., 1998), anti-Nkx2.2 antibody used at 1:2 dilution (74.5A5) (Ericson et al., 1996), anti-Shh antibody used at 1:8 (5E1) (Ericson et al., 1996), and anti-hepatocyte nuclear factor $3 \beta(\mathrm{HNF} 3 \beta)$ antibody used at 1:4 dilution (4C7) (Ericson et al., 1996).

The $\mathrm{O} 4$ primary antibody was directly applied to tissues and left overnight at $4^{\circ} \mathrm{C}$. For detection of intracellular antigens, tissues were first permeabilized using Triton X-100 (Sigma) at $0.5 \%$ in PBS, and adequate primary antibody was further applied at the appropriate dilution in $0.1 \%$ Triton X-100/PBS and incubated overnight at $4^{\circ} \mathrm{C}$. Tissues were rinsed and incubated for $45 \mathrm{~min}$ with biotinylated secondary antibody directed against mouse Ig (diluted 1:50; Amersham Biosciences, Arlington Heights, IL). Biotinylated antibodies were revealed by incubation for 15 min with FITC (fluorescein isothiocyanate) or TRITC (tetramethylrhodamine isothiocyanate)-coupled streptavidin (1:50; Amersham Biosciences).

For detection of Shh protein on living tissues, the 5E1 anti-Shh antibody was added to the culture medium at a 1:8 final dilution and incubated for $45 \mathrm{~min}$ at $38^{\circ} \mathrm{C}$. The washes were realized in Tyrode's solution (Sigma), and revelation was performed using the secondary antibodies described above. Explants were then fixed for $15 \mathrm{~min}$ in $3.7 \%$ formaldehyde/PBS at room temperature. In double-staining experiments to detect Nkx2.2, once the Shh immunodetection has been performed, the explants were sectioned and the standard immunostaining procedure was performed on sections.

Sections and explants were then analyzed with a Leica SP2 confocal microscope. Image analysis of Shh distribution on live flat-mounted spinal cords was performed using Image J software on confocal images. Mean pixel intensity was measured across the image, in units of $25 \mu \mathrm{m}$ square areas, from the spinal cord ventral midline to the lateral side of the spinal cord. Values were then expressed as the percentage of the mean pixel intensity of the first, most medial, area. Measurements were performed on at least three different preparations. 
In situ hybridization. Nonradioactive in situ hybridization on vibratome sections of chick embryos or explants in culture were performed as described previously (Mekki-Dauriac et al., 2002; Agius et al., 2004; Braquart-Varnier et al., 2004). Briefly, vibratome sections $(80 \mathrm{~mm}$; Leica) were obtained from the cervicobrachial region of whole embryos, dehydrated in ethanol, and stored at $-20^{\circ} \mathrm{C}$. Digoxigenin (DIG)-labeled sense and antisense RNA probes were synthesized using T3 and T7 polymerases. The probes were detected with alkaline phosphatase (AP)conjugated anti-DIG (Boehringer, Mannheim, Germany). The substrate for AP was 5-bromo-4-indoyl phosphate (BCIP)/nitroblue tetrazolium chloride (NBT) (Boerhinger).

The following chick gene probes were used: Patched and shh (a gift from Dr. C. Tabin), Sim1 (a gift from Dr. J. Michaud, Hopital SainteJustine, Montreal, Quebec, Canada), NeuroM (a gift from Dr. M. Ballivet, University of Geneva, Geneva, Switzerland), Ebf2 (a gift from Dr. A. Vincent, Centre National de la Recherche Scientifique/Université Paul Sabatier, Toulouse Cedex, France), Olig2 and Ngn2 (provided by Dr. D. Anderson, California Institute of Technology, Pasadena, CA), Ext1 (obtained from University of Delaware, Newark, DE; clone pc01c.pk001.c19), and Sulf1 (Braquart-Varnier et al., 2004).

Gfp probe was obtained from a PCR-amplified fragment using the following primers: $5^{\prime}$-AGTTCATCTGCACCACC-3' and 5'-GTAATACGACTCACTATAGGGCTTGTACAGCTCG-3'.

Double-label in situ hybridization was performed using two different probes labeled with either digoxigenin or fluorescein. The first probe was detected with AP-conjugated anti-digoxigenin antibody, developed with NBT and BCIP, which yields a purple precipitate. After the NBT/BCIP reaction, the AP-conjugated antidigoxigenin antibody was inactivated at $85^{\circ} \mathrm{C}$, and the sections were subsequently incubated with AP-conjugated anti-fluorescein antibody, and detected with INT (2-[4-iodophenyl]-3[4-nitrophenyl]-5-phenyl terazolium chloride) and BCIP, which yield a reddish brown precipitate. Stained sections were digitalized and analyzed using Zeiss (Oberkochen, Germany) software, and images were manipulated using Adobe Photoshop.

\section{Results \\ OLP specification correlates with the end of neuronal production in the $\mathrm{Nkx} 2.2$ domain of the ventral neuroepithelium}

In the embryonic chick spinal cord, ventral Nkx2.2-expressing progenitors are specified to become OLPs between E5 and E5.5/E6 (Soula et al., 2001; Zhou et al., 2001) and newly determined OLPs can be identified by the precocious and specific marker O4 (Ono et al., 1995; Miller et al., 1997; Soula et al., 2001). During early neural tube development, Nkx2.2 expression defines the ventral-most p3 domain of the neuroepithelium that generates V3 ventral interneurons (Briscoe et al., 1999) but is exclusive of the overlying Olig2-expressing pMN domain (Fig. 1A) (Mizuguchi et al., 2001; Novitch et al., 2001). From E5 onwards, the Nkx2.2 progenitor domain extends dorsally leading to formation of the $\mathrm{p}^{\star}$ domain characterized by the coexpression of Olig2 and Nkx2.2 (Fig. 1 B,E) (Zhou et al., 2001; Fu et al., 2002; Agius et al., 2004). At their time of appearance (E5.5/E6), immunodetection using $\mathrm{O} 4$ antibody allowed detection of the two different subsets of ventral OLPs that coexist in the ventral neuroepithelium, one defined by a Nkx2.2+/Olig2+ code and the other, located more ventrally, exhibiting a Nkx2.2+/Olig2code (Fig. 1D,F) (Zhou et al., 2001; Fu et al., 2002). Therefore, $\mathrm{O} 4$ antibody identifies the entire OLP population of the ventral OL domain. It is now well established that neural progenitors of the Olig2+ domain cease to generate MNs when they gain the expression of Nkx2.2 and switch to an OL fate (Soula et al., 2001; Kessaris et al., 2001; Rowitch, 2004). We therefore asked whether a similar switch between V3 ventral interneurons and OLPs occurs in the ventral-most Nkx2.2+/Olig2- p3 domain. To define the period of $\mathrm{V} 3$ neuron production from ventral neuroepithelial cells, we used an assay system developed previously to determine the timing of MN and OL genesis, in which neural progenitors of the ventral neuroepithelium are isolated at various stages of development and allowed to differentiate in vitro (Soula et al., 2001). Under such conditions, neuroepithelial cells are no longer exposed to possible inducing or repressing influences from the surrounding tissues and differentiate according to intrinsic potentialities acquired before their isolation. Ventral neuroepithelial explants encompassing at least the $\mathrm{p} 3$ and $\mathrm{pMN}$ domains were isolated at E4.5 and E6/E7, and their ability to generate V3 neurons was analyzed using $\operatorname{sim} 1$ as a specific marker (Fan et al., 1996). A large fraction of ventral neuroepithelial explants (80\%) isolated at E4.5 generated numerous sim $1+$ neurons that could be detected after $2 \mathrm{~d}$ in culture (Fig. $1 G$ ) but no O4+ oligodendrocytes (data not shown) (Soula et al., 2001). In contrast, we never observed differentiation of V3 neurons from neural precursors isolated at E6/E7 (Fig. $1 \mathrm{H}$ ), but numerous oligodendrocytes could be detected (data not shown) (Soula et al., 2001). These results show that the production of V3 neurons ceases in the ventral neuroepithelium between E4.5 and E6/E7 (i.e., at the same time as $\mathrm{MN}$ genesis is ending in this region and immediately before OL genesis).

To confirm these results, we analyzed the temporal expression of general markers of neuronal genesis, the transcription factors Ebf2 and NeuroM, which are involved in early steps of neuronal differentiation (Garel et al., 1997; Roztocil et al., 1997; Dubois et al., 1998). Expression of ebf2 and neuroM in the ventral spinal cord was assessed around the time of OLP induction. Until E4.5/ E5, both ebf2 and neuroM mRNA were detected in bilateral stripes of cells located throughout the dorsoventral axis of the neuroepithelium, at the interface between the proliferative and postmitotic regions of the developing spinal cord, indicating that neurons are generated at all of the dorsoventral levels of the neuroepithelium at this stage (Fig. $1 I, K$ ). At E6/E7, the persistence of ebf 2 and neuro $M$ expression in intermediate and dorsal domains of the spinal cord showed that neuronal genesis was still occurring in these regions (Fig. $1 \mathrm{~J}, L$ ). In contrast, expression of both genes had disappeared in the ventral region of the spinal cord, flanking the floor plate (Fig. $1 \mathrm{~J}, L$ ), indicating that neurons are no longer produced from the ventral-most neural progenitors at this stage.

Together, these results show that neural progenitors of the $\mathrm{p} 3$ domain stop producing V3 ventral interneurons when OLP specification begins. Thus, the principle of the N/OL switch, well described for progenitors of the pMN domain, can be generalized to the entire population of ventral OLP progenitors in the chicken spinal cord.

\section{Increasing Shh levels is sufficient both to induce premature oligodendroglial specification and to inhibit neuronal production in the ventral neuroepithelium}

Specification of ventral neurons during early phases of neurogenesis (from E1.5 in chicken neural tube) depends on the graded morphogen activity of Shh, which controls the emergence of the distinct ventral neuronal subtypes in a precise spatial and temporal order (Briscoe et al., 2000; Jessell, 2000; Briscoe and Ericson, 2001; Stamataki et al., 2005). Similarly, Shh has been shown to be required for the initial step of OLP induction, which occurs in a very narrow time window, between E5 and E5.5 in chicken (Orentas et al., 1999; Soula et al., 2001) and to be sufficient to induce OLPs from neuroepithelial cells at various stages of development (Poncet et al., 1996; Pringle et al., 1996; Soula et al., 2001). In other words, the induction of ventral neurons and that 

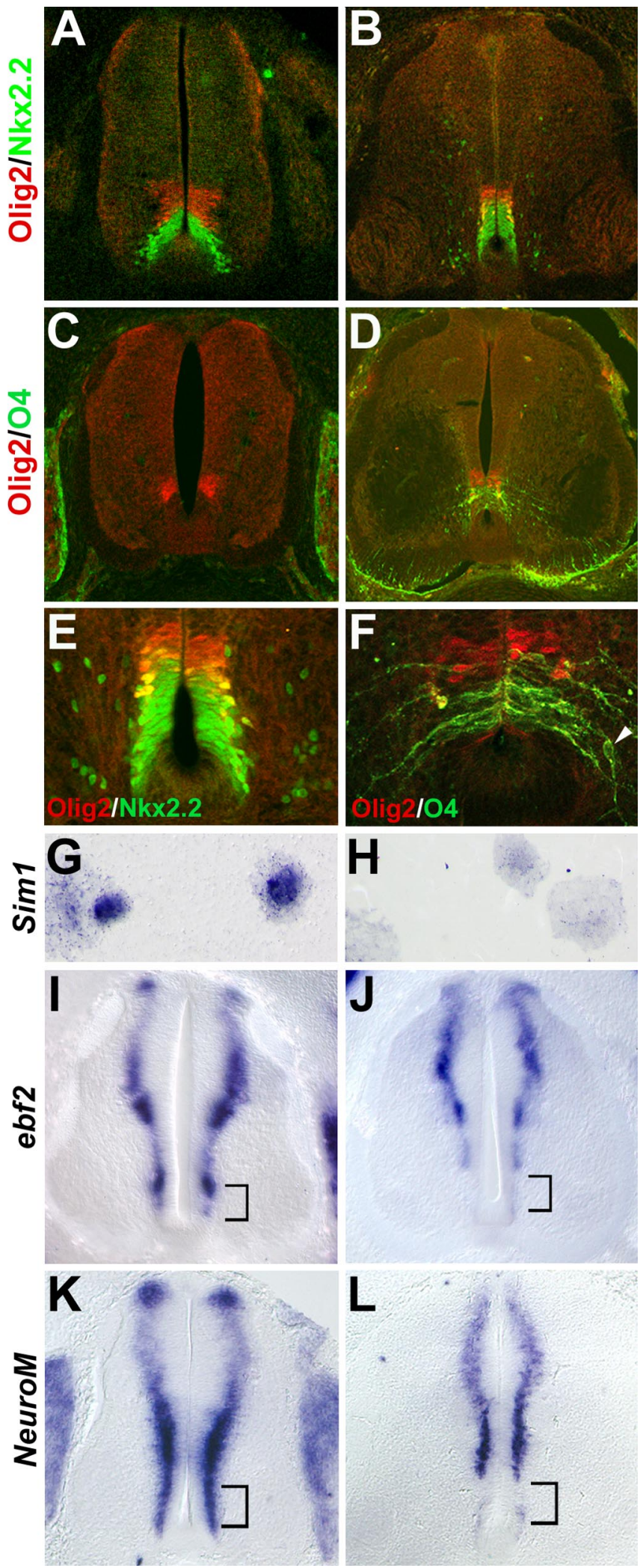

Figure 1. OLP specification from $N k \times 2.2$-expressing progenitors correlates with the end of neuronal production in the ventral spinal cord. $\boldsymbol{A}-\boldsymbol{F}$, Immunodetection of 0 lig2, Nkx2.2, and 04 on transverse sections of $E 4(\boldsymbol{A}, \boldsymbol{C})$ and $E 6(\boldsymbol{B}, \boldsymbol{D}, \boldsymbol{E}, \boldsymbol{F})$ spinal cords. $\boldsymbol{A}, \boldsymbol{B}, \boldsymbol{E}$, Double immunodetection of Olig2 (red) and Nkx2.2 (green) showing the mutually exclusive spatial 0lig2 + pMN domain and $\mathrm{Nkx2.2}+\mathrm{p} 3$ domain at $\mathrm{E} 4(\boldsymbol{A})$ and the formation of the 0 lig2 $+/ \mathrm{Nk} \times 2.2+\mathrm{p}^{*}$ domain at $\mathrm{E} 6(\boldsymbol{B})$. $\boldsymbol{E}$, Higher magnification of $\boldsymbol{B}$, showing the coexpression of Olig2 and Nkx2.2 in the nascent $p^{*}$ domain, whereas the ventral-most Nkx2.2+ cells of the $\mathrm{p} 3$ domain do not express 0lig2. C, D, F, Double immunodetection of 0lig2 (red) and 04 (green). 04+ cells were of OL cells occur sequentially from the same set of neural progenitors under the control of Shh. The mechanism underlying this temporal switch of neuroepithelial progenitor cells in response to Shh remains to be elucidated. An attractive hypothesis is that this switch occurs in response to a sudden increase of Shh signaling at this time. This is strongly supported by previous data showing that OLP specification from ventral neural progenitors is optimal at concentrations of Shh much higher than those reported to induce MNs and V3 neurons from neural progenitors (12-25 and 2-4 nM, respectively) (Briscoe and Ericson, 1999; Soula et al., 2001). Furthermore, the dorsal expansion of Nkx2.2, a Shh-responsive gene (Briscoe et al., 1999), at the time of OLP specification in vivo is consistent with there being a temporal increase of Shh signaling (Zhou et al., 2001; Agius et al., 2004). This hypothesis implies that an increase of Shh concentration during the early period of neuronal production would be sufficient to induce prematurely a N/OL switch in the ventral neuroepithelium.

To test this prediction, E1.5 whole neural tube explants, including Shh-producing floor plate cells, were exposed to various concentrations of Shh, and the timing of MNs and OL differentiation was further assessed using MNR2 (Tanabe et al., 1998) and $\mathrm{O} 4$. In control explants grown for $3 \mathrm{~d}$ without addition of Shh, MNR2 + cells were invariably detected in narrow columns of cells flanking the midline (Fig. $2 \mathrm{~A}$ ). In contrast, $\mathrm{O} 4+$ cells were never detected in 3-d-old explants (Fig. 2C). The presence of $\mathrm{O} 4+$ cells was first observed after $5 \mathrm{~d}$ in culture (data not shown), consistent with the normal timing of $\mathrm{O} 4$ expression in vivo (E5.5/ E6). Neural tube explants were then exposed to concentrations of Shh ranging from 25 to $100 \mathrm{~nm}$. These concentrations of Shh, very high compared with those required to pattern the ventral neural tube (2-4 nM), have been shown previously to be optimal in inducing Olig2/Nkx2.2 coexpression and OLP specification in E5 ventral neuroepithelial explants (Soula et al., 2001; Agius et al., 2004). A significant reduction in the number of MNR2 + cells was observed in neural tube explants cultivated for $3 \mathrm{~d}$ in the presence of 25-50 nM Shh (data not shown), and only a few MNR2+ cells were detected in the presence of $100 \mathrm{~nm}$ Shh (Fig. $2 \mathrm{~B})$. Conversely, the addition of $100 \mathrm{~nm}$ Shh to the culture medium invariably induced differentiation of $\mathrm{O} 4+$ cells as early as $3 \mathrm{~d}$ after plating, indicating that production of OLPs had been advanced compared with the normal timing of their appearance both in vitro and in vivo (Fig. $2 D$ ). Under the same culture conditions, the distribution of $\mathrm{Nx} 2.2+$ cells, restricted to bilateral column of cells in control explants (Fig. 2E), dramatically changed when $100 \mathrm{~nm}$ Shh has been added to the culture medium. Confocal analysis reveals that these cells were no longer located in the neuroepithelial layer but had moved into the un-

never found in E4 spinal cord (C). Note the detection of 04 expression in dorsal root ganglia ( $\boldsymbol{A}$, arrowheads). At E6, $04+0 \mathrm{LP}$ are detected in the ventral-most region of the neuroepithelium, adjacent to the floor plate. $\boldsymbol{F}$, Higher magnification of the ventral neuroepithelium showing the coexistence of 0lig $2+/ 04+$ and 0 lig2 $-/ 04+$ cells in the $p^{*}$ and $p 3$ domains, respectively. Note that, at this stage, 0 lig2 $-104+$ cells were already migrating away from the neuroepithelium ( $\boldsymbol{F}$, arrowhead). $\boldsymbol{G}, \boldsymbol{H}$, Ventral neuroepithelial explants isolated from E4 $(\boldsymbol{G})$ and E7 $(\boldsymbol{H})$ embryos and maintained $2 \mathrm{~d}$ in culture. Detection of $\operatorname{sim} 1$ by in situ hybridization shows that $\mathrm{V} 3$ ventral interneurons differentiate from E4 $(\boldsymbol{G})$ but not from E7 ventral neural progenitors $(\boldsymbol{H})$. $\boldsymbol{I}-\boldsymbol{L}$, Detection of ebf2 and neuroM on transverse vibratome sections of $\mathrm{E} 4(\boldsymbol{I}, \boldsymbol{K})$ and $\mathrm{E} 6(\boldsymbol{J}, \boldsymbol{L})$ spinal cords. At E4, both neuronal markers are detected all along the dorsoventral axis of the spinal cord in cells lining the neuroepithelium $(\boldsymbol{I}, \boldsymbol{K})$, whereas at E6, ebf2 and neuroM expressions have disappeared in the region adjacent to the ventral-most domain of the neuroepithe$\operatorname{lium}(\boldsymbol{J}, \boldsymbol{L}$, brackets). 

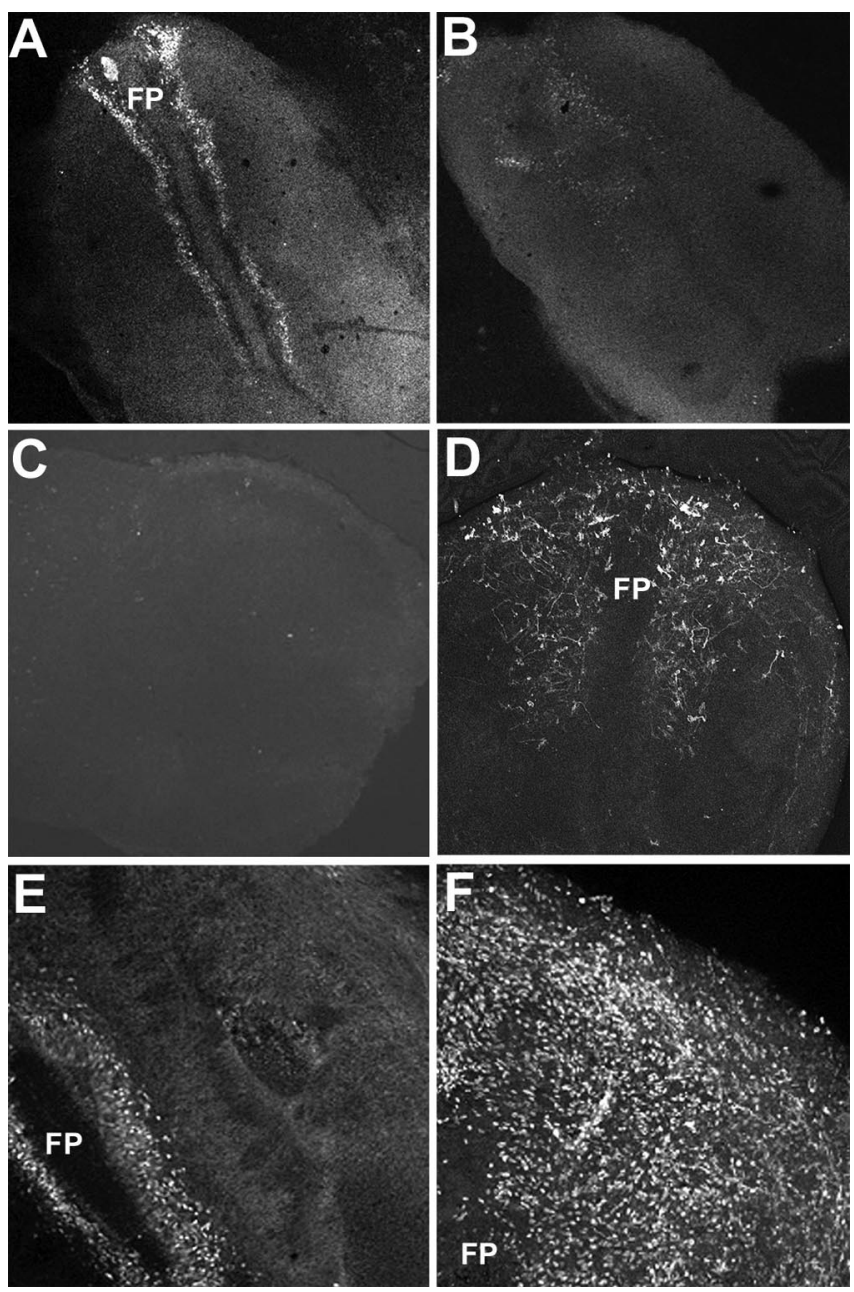

Figure 2. A high concentration of Shh inhibits MN differentiation and induces precocious emergence of $0 \mathrm{LP}$ in neural tube explants. E1.5 flattened neural tube explants were cultivated for $3 \mathrm{~d}$ in the absence $(\boldsymbol{A}, \boldsymbol{C}, \boldsymbol{E})$ or in the presence $(\boldsymbol{B}, \boldsymbol{D}, \boldsymbol{F})$ of $100 \mathrm{~nm}$ Shh. $\boldsymbol{A}, \boldsymbol{B}$, MNs were identified by their expression of MNR2 in E1.5 neural tube explants cultivated for $3 \mathrm{~d}$. Without addition of Shh, MN differentiation is observed in the ventral region of the neural tube explants $(\boldsymbol{A})$, whereas in presence of $100 \mathrm{~nm}$ Shh, the number of MNR2 + cells is greatly reduced $(\boldsymbol{B}) . \boldsymbol{C}, \boldsymbol{D}$, Immunodetection using the 04 antibody shows that in control conditions neural progenitors do not generate 0 LPs after $3 \mathrm{~d}$ in culture (C). In contrast, addition of $100 \mathrm{~nm}$ Shh leads to differentiation of $04+$ cells as soon as $3 \mathrm{~d}$ after plating (D). $\boldsymbol{E}, \boldsymbol{F}$, Without addition of Shh, Nkx2.2expressing cells were detected in the ventral-most region of the neuroepithelium, adjacent to the floor plate $(\boldsymbol{E})$. In the presence of Shh, numerous scattered Nkx2.2 + cells have emigrated at the periphery of the explants $(\boldsymbol{D})$. FP, Floor plate.

derlying tissue (Fig. $2 F$ ). As Nkx2.2 has been shown to be expressed in migratory OLPs in the chicken embryo (Xu et al., 2000; Zhou et al., 2001; Fu et al., 2002), these results may reflect the consequence of an early migration of OL cells.

Together, these results show that elevating Shh concentration in the E1.5 neural tube explants is sufficient to induce premature OLP differentiation in vitro. This was accompanied by a dosedependent reduction in the number of MNs differentiating in these cultures, suggesting that neural progenitors subjected to high concentrations of Shh prematurely switched toward an OL fate at the expense of $\mathrm{MN}$ production.

We then asked whether increasing Shh activity in the E1.5 neural tube would be sufficient to change the timing of OLP specification in vivo. We used two distinct methods to achieve this: in ovo electroporation of a Shh-expressing vector and insertion of quail QT6 fibroblasts that constitutively express Shh
(QT6-Shh cells) (Riddle et al., 1993). Embryos were harvested 2-6.5 d later (E3.5-E8), and expression of OLP and neuronal markers was assessed on transverse spinal cord sections.

In embryos fixed at E3.5 (i.e., 2 d before the earliest O4expressing cells are normally found), Shh overexpression by electroporation led to precocious appearance of $\mathrm{O} 4+$ cells located in the ventral neuroepithelium (Fig. $3 A, D$ ). These cells displayed the characteristic radial morphology of ventral OLP, with the cell body located in the neuroepithelium (Fig. 3D). At E4.5, when OLPs have not yet been specified on the control side, as testified by the absence of $\mathrm{O} 4$ detection, numerous $\mathrm{O} 4+$ cells were detected on the electroporated or grafted side of the spinal cord (Fig. $3 B, E$ ). Strikingly, induced $\mathrm{O} 4+$ cells were always included in the ventral neuroepithelium, even in embryos in which Shh was misexpressed both in dorsal and ventral regions of the neural tube (Fig. 3A). At E5.5/E6, when endogenous OLPs can just be detected in the spinal cord, but when overt OL differentiation has not yet occurred (Ono et al., 1995; Soula et al., 2001), O4+ neuroepithelial cells extended dorsally on the side overexpressing Shh compared with the contralateral side (Fig. 3C), revealing a dorsal expansion of the OL domain. Interestingly, Shh-induced OLs were observed at some distance from the ventricular zone and some of them had already reached the marginal zone (Fig. $3 F$ ), indicating a precocious migration of OL cells. These experiments clearly show that raising the doses of Shh in the early neural tube is sufficient to induce premature emergence of $\mathrm{O} 4+$ OLPs in the ventral neuroepithelium as well as premature migration of these cells in the presumptive white matter.

To further assess the oligodendroglial nature of the prematurely induced $\mathrm{O} 4+$ cells, we analyzed expression of $\mathrm{Nkx} 2.2$ and Olig2. At E4.5, in agreement with the known positive regulation of Nkx2.2 by Shh (Briscoe et al., 1999), the Nkx2.2 domain of the ventricular zone was invariably expanded dorsally on the electroporated or grafted side (Fig. $3 G$ ). At the same stage, we observed that some Nkx2.2 + cells had emigrated in the mantle layer and colonized the forming marginal zone on the side of the spinal cord submitted to high Shh signaling (Fig. 3G,H). Such cells were never observed in the marginal zone of the control side (Fig. $3 G$ ), and colonization of this region has been shown to occur only from E7 during normal spinal cord development (Xu et al., 2000; $\mathrm{Fu}$ et al., 2002). Analysis at a later stage, E8, showed that the domain of $n k x 2.2$ expression in the ventricular zone was still dorsally expanded, and a higher number of $n k x 2.2$-expressing cells was observed in the marginal zone of the electroporated side compared with the control side (Fig. $3 I$ ). Nkx2.2-expressing cells migrating in the presumptive white matter have been identified as OL cells (Xu et al., 2000; Fu et al., 2002). Thus, our results showing premature colonization of this particular region of the spinal cord by Nkx2.2-expressing cells support the conclusion that an enhancement of Shh signaling leads to an early production of OL cells.

Analysis of olig2 expression at E4 showed a similar extension of the olig2-expressing domain in the ventral neuroepithelium (Fig. $3 H$ ). Some cells emigrating from the olig2-expressing domain were observed at E4.5/E5 (i.e., $2 \mathrm{~d}$ in advance compared with normal development) (Fig. $3 \mathrm{~K}$ ), and at E8, we noticed the presence of olig2 + cells that have already reached the intermediate marginal zone on the electroporated side of the spinal cord (Fig. 3L).

Together, these results show that the specification of OLPs from ventral neural progenitors of the spinal cord is anticipated by elevating Shh signaling and that this results in premature col- 

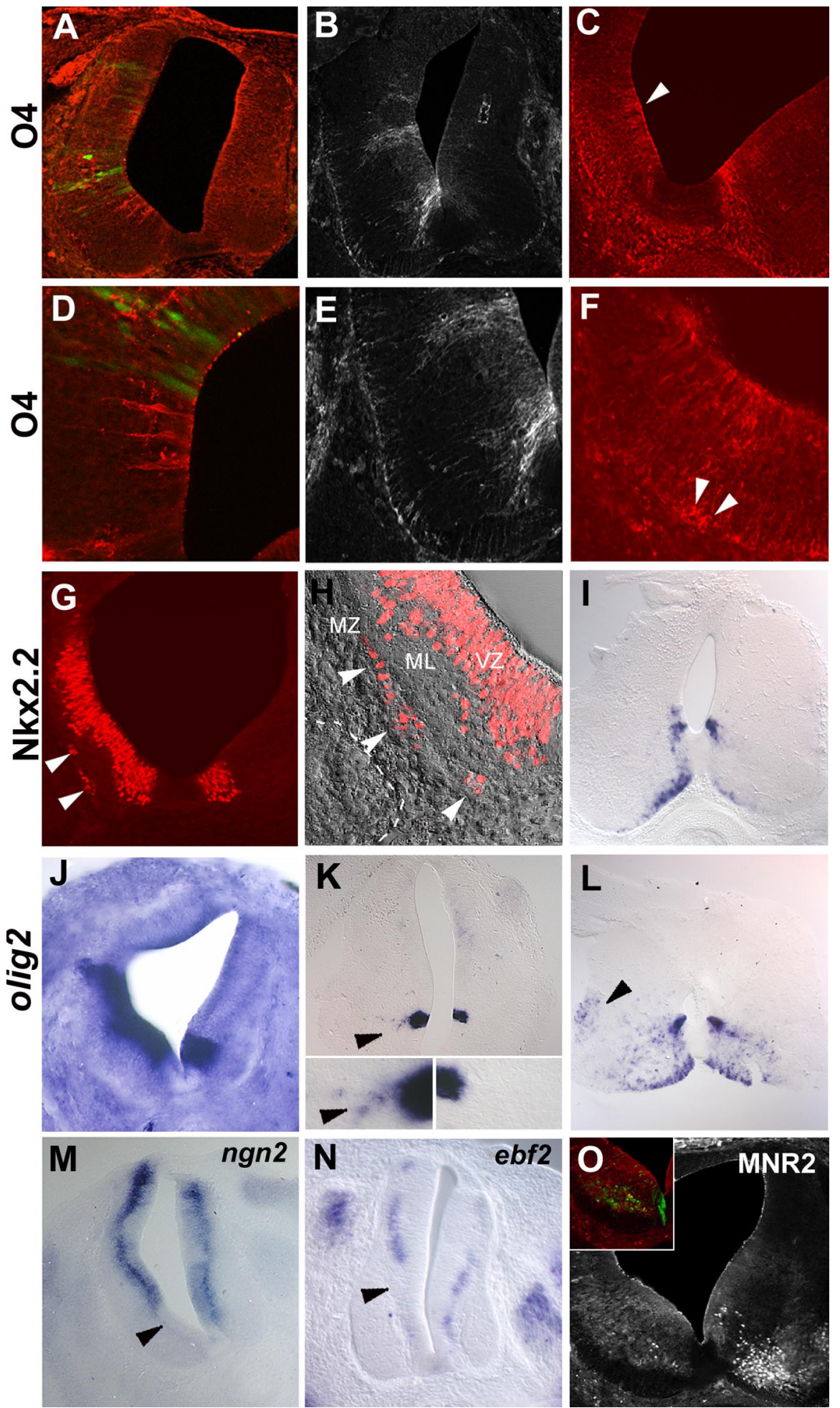

Figure 3. Elevating the doses of Shh in the E1.5 neural tube induces premature OLP specification and inhibits neuronal production in the ventral spinal. Early neural progenitors (E1.5) have been submitted to high activity of Shh by electroporation of a Shh-expressing vector $(\boldsymbol{A}-\boldsymbol{F}, \boldsymbol{I}, \boldsymbol{K}-\boldsymbol{M}, \mathbf{0})$ or graft of Shh-expressing cells $(\boldsymbol{G}, \boldsymbol{H}, \boldsymbol{J}, \boldsymbol{N})$. The side of electroporation or graft is represented on the left in each picture. $\boldsymbol{A}, \boldsymbol{B}, \boldsymbol{D}, \boldsymbol{E}$, Electroporation of a Shh-expressing vector results at $\mathrm{E} 3.5$ in the emergence of premature 04-expressing cells (red) in the ventral spinal cord $(A, D)$. At E4.5, numerous prematurely induced $04+$ cells were detected $(\boldsymbol{B}, \boldsymbol{E})$. Note the absence of $04 \mathrm{imm}$ unoreactivity in the control side at both stages. $\boldsymbol{D}, \boldsymbol{E}$, High magnifications showing that $04+$ cells are located in the neuroepithelium. $\boldsymbol{C}-\boldsymbol{F}$, At E6, electroporation of Shh causes dorsal extension of the $0 \mathrm{~L}$ domain (C, arrowhead) compared with the nonelectroporated side ( $\boldsymbol{C}$, right). At higher magnification, $04+$ cell bodies can be already detected at the periphery of the spinal cord ( $\boldsymbol{F}$, arrowheads). $\mathbf{G}-\boldsymbol{I}$, Graft of Shh-expressing cells results at E4 in dorsal extension of the Nkx2.2-expressing domain of the ventricular zone. Note the presence of ectopic $\mathrm{Nkx2.2}+$ cells located in the marginal zone $(\boldsymbol{G}$, arrowheads), whereas such cells are not detected in the contralateral side. MZ, Marginal zone; ML, mantle layer; VZ, ventricular zone. $\boldsymbol{H}$, Overlay of immunostaining and Nomarski images at high magnification of ventrolateral part of grafted spinal cord onization of the presumptive white matter by differentiating OL cells.

We then investigated whether the premature specification of OLPs induced by Shh overexpression was accompanied by an inhibition of neuronal genesis in the ventral neuroepithelium. We first examined the expression patterns of the proneural gene $n g n 2$, known to be downregulated in the pMN domain shortly after the end of the period of $\mathrm{MN}$ production (Zhou et al., 2001). We invariably observed that the ventral limit of the ngn2expressing domain was shifted dorsally on the Shh-overexpressing side compared with the contralateral side, leading to a large ventral region devoid of $n g n 2$ transcripts (Fig. $3 M$ ). This result shows that high doses of Shh are able to inhibit $n g n 2$ expression in ventral neural progenitors as early as E4, whereas this downregulation normally occurs between E5 and E6 in the pMN domain (Zhou et al., 2001). To determine whether repression of $n g n 2 \mathrm{ex}$ pression reflected the inability of ventral progenitors to produce neurons, we analyzed ebf2, neuro $M$, and MNR2 expression in spinal cords subjected to high Shh concentrations from E1.5. On the treated side, both in electroporation and graft experiments, a downregulation of ebf2 (Fig. $3 N$ ) and neuroM (data not shown) could already be observed in the ventral region at E3.5/E4, whereas their expression remained unaffected on the control side (Fig. 3N) (data not shown). Likewise, at E6, we observed a dramatic decrease in the

showing the presence of $\mathrm{Nk} \times 2.2+$ cells in the forming marginal zone (white arrowheads delineate the pial surface of the spinal cord; the dashed line indicates the position of grafted QT6-Shh cells). At E8, numerous nkx2.2-expressing cells were accumulated in the marginal zone, whereas only a few of them were detected in the control side $(\boldsymbol{I})$. $J-L$, Detection of olig2 transcript by in situ hybridization. At E4, a marked extension of the olig2-expressing domain is observed in grafted embryo $(J)$. At E4.5/E5 in an electroporated embryo, few olig2 + cells emigrating from the 0lig2expressing neuroepithelial domain were observed $(\boldsymbol{K}$, arrowheads), whereas such migration is not noticed in the control side $(\boldsymbol{K})$. The insets in $\boldsymbol{K}$ show high magnification of olig2expressing domains of the ventral neuroepithelium and olig2 + emigrating cells in the electroporated side (arrowhead). At E8, olig2-expressing cells have already reached the intermediate marginal zone of the spinal cord $(\boldsymbol{L}$, arrowhead). $\boldsymbol{M} \mathbf{- 0}$, Inhibition of ventral neuronal genesis by high doses of $S h h$ in the embryonic spinal cord. Detection of neuronal precursors using $n g n 2(\boldsymbol{M})$ and ebf2 $(\boldsymbol{N})$ on transverse sections of $E 4$ embryos electroporated or grafted at E1.5. Note the extinction of neuronal markers on the operated side $\boldsymbol{M}$, $\boldsymbol{N}$, arrowheads) compared with the contralateral side. $\mathbf{0}, \mathrm{At}$ E6, immunodetection using MNR2 shows a strong inhibition of MN differentiation in the electroporated side $(\boldsymbol{0}$, inset). 

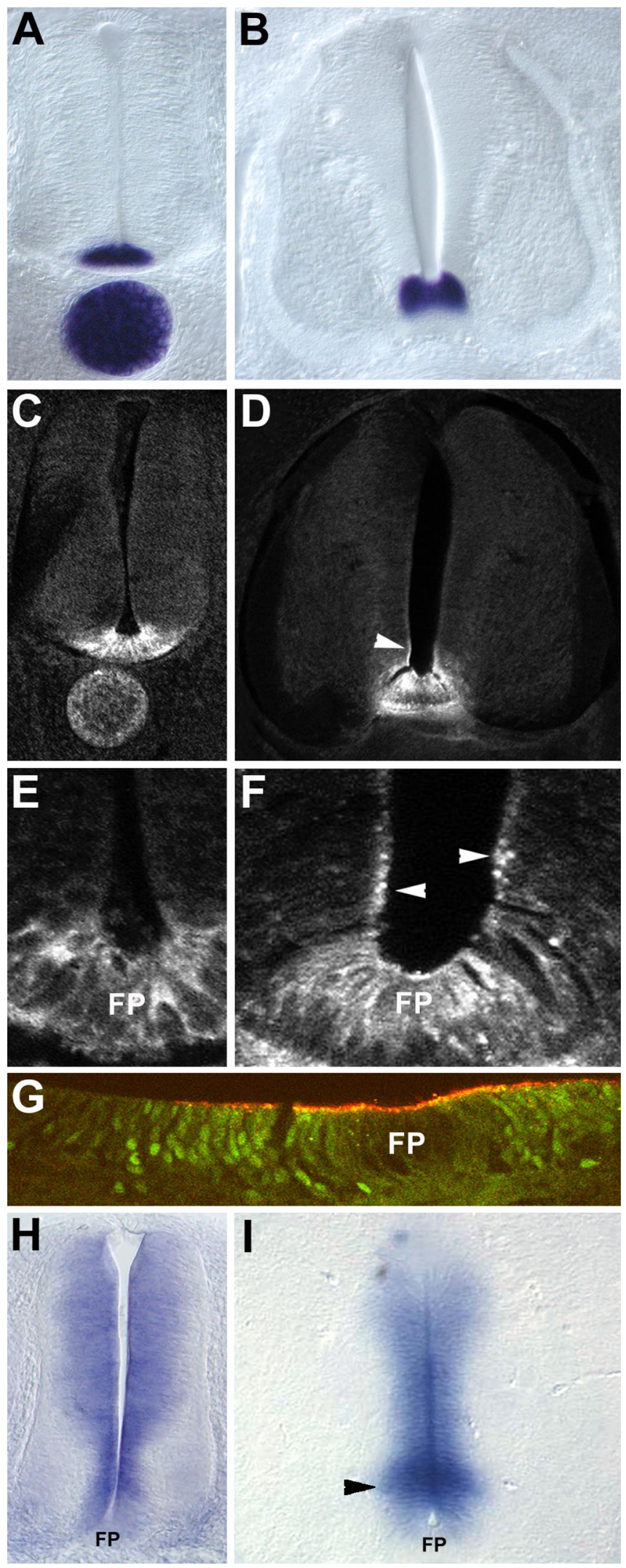

Figure 4. Shh protein accumulates at the surface of Nkx2.2-expressing neural progenitors before OLP specification. $\boldsymbol{A}, \boldsymbol{B}$, Detection of shh mRNA by in situ hybridization on a transverse section of $\mathrm{E} 3$ and $\mathrm{E} 5$ embryos. Note that the messenger is restricted to floor plate cells at these stages. $\boldsymbol{C}-\boldsymbol{F}$, Immunodetection of Shh on transverse sections of $\mathrm{E} 3(\boldsymbol{C}, \boldsymbol{E})$ and $\mathrm{E} 5(\boldsymbol{D}, \boldsymbol{F})$ spinal cords. $\boldsymbol{E}, \boldsymbol{F}$, Higher magnifications of $\boldsymbol{C}$ and $\boldsymbol{D}$, respectively. During neuronal production (E3), Shh protein was detected in producing tissues (i.e., floor plate and notochord) $(\boldsymbol{C}, \boldsymbol{E})$. At E5, bright, punctate Shh immunoreactivity was visualized at the surface of the ventral-most neuroepithe- number of MNR2+ cells on the treated side, indicating strong inhibition of MNs differentiation, in agreement with the inhibition observed in neural tube explants (Fig. 3O).

These results show that when the dose of Shh was raised from E1.5, ventral neural progenitors ceased to generate neurons $2-3 \mathrm{~d}$ earlier than during normal development.

To define whether the phenotype we obtained was attributable to ectopic induction of floor plate cells, we analyzed the expression of HNF3 $\beta$ in E3.5 spinal cords subjected to high Shh activity. This specific floor plate marker was not induced by Shh overexpression (data not shown), as reported previously (Patten and Placzek, 2002).

Together, these results show that exposing E1.5 neural progenitors to high doses of Shh is sufficient to promote early induction of ventral OLPs and concomitant inhibition of neuronal genesis, supporting the view that ventral neural progenitors switch from neuronal to oligodendroglial fate in response to a temporal increase of Shh activity in the ventral neural tube.

\section{Shh accumulates at the apical surface of $\mathrm{Nkx2}$.2-expressing} neuroepithelial cells before the N/OL switch in this domain The above data support the view that an abrupt increase in Shh signaling at the time of OLP specification is instrumental in triggering the N/OL switch. We then asked whether a change in the pattern of expression of Shh mRNA and/or protein can be detected around the time of OLP induction in the ventral spinal cord. We first compared the pattern of expression of shh mRNA at E3 and E5 by in situ hybridization on transverse spinal cord sections. Under identical experimental conditions, shh mRNA was detected in floor plate cells at both stages with a similar pattern and intensity of expression (Fig. 4A,B). We then analyzed the pattern of expression of the protein using the $5 \mathrm{E} 1$ antibody, which recognizes the biologically active $\mathrm{N}$-terminal fragment of Shh (Ericson et al., 1996). This analysis was performed on transverse sections of spinal cord fixed in ethanol/acetic acid fixative, which preserves extracellular molecules (Gritli-Linde et al., 2001). At E3, Shh was detected in Shh-producing cells (i.e., in the notochord and floor plate but not in Shh-responsive cells of the neuroepithelium), indicating that the level of Shh protein in this tissue is below the detection limit (Fig. 4C,E). At E5, in addition to persisting staining of the notochord and floor plate tissues, bright punctate staining was observed at the luminal surface of the ventral-most neuroepithelial cells, whereas no signal was detected inside the cell bodies (Fig. $4 D, F$ ). This change in Shh staining between E3 and E5 shows that the protein is concentrated at the apical surface of ventral neural progenitors before OLP induction. The absence of detectable expression of shh mRNA in ventral neuroepithelial cells at this stage (Fig. $4 B$ ) indicates that the presence of Shh at their surface results from local accumulation of the protein synthesized by floor plate cells. To map the dorso-ventral extent of Shh protein accumulation in the ventral neuroepithelium, we compared the patterns of expression of Shh and Nkx2.2 by double immunostaining. To circumvent

lial cells ( $\boldsymbol{D}, \boldsymbol{F}$, arrowheads). $\boldsymbol{G}$, Double immunostaining of Shh (red) and Nk2.2 (green) on transverse section of flattened spinal cord explant isolated at $E 4$ and maintained a day in culture. The floor plate delineates the ventral midline flanked by the bilateral Nkx2.2 neuroepithelial domain (green). Note that the Shh punctate staining extends precisely over the Nkx2.2expressing domain of the ventral neuroepithelium. $\boldsymbol{H}, \boldsymbol{I}$, Detection of ptc mRNA by in situ hybridization on transverse E3 $(\boldsymbol{H})$ and E7 $(\boldsymbol{I})$ spinal cords. Note the presence of a domain of strong expression in the ventral-most region of the neuroepithelium at $\mathrm{E}$ ( $\boldsymbol{I}$, arrowhead). FP, Floor plate. 
the loss of Nkx2.2 immunoreactivity in ethanol/acetic acid-fixed spinal cord, we turned to an in vitro model system of flat wholemount spinal cord culture that we recently developed (MekkiDauriac et al., 2002; Agius et al., 2004). Explants were cultured for a day, immunostained live with the $5 \mathrm{E} 1$ antibody, fixed in formaldehyde, and then counterstained for Nkx2.2. Confocal analysis of transverse sections of the explants confirmed the detection of Shh aggregates at the apical surface of ventral neural progenitors and showed that the domain of Shh accumulation precisely overlapped the Nkx2.2-expressing domain of the neuroepithelium (Fig. 4G).

To determine whether the accumulation of Shh protein between E3 and E5 resulted in functional activation of Shh signaling in ventral neural progenitors, we examined the expression of patched ( $p t c)$, as a transcriptional readout of Shh activity (Goodrich et al., 1996). At E3, ptc expression was detected in both ventral and dorsal parts of the neuroepithelium (Fig. 4H). The intensity of the staining, decreasing ventrodorsally, revealed the graded Shh activity described previously in the neural tube (Marigo and Tabin, 1996). At E5, when Shh could just be detected at the luminal surface of neuroepithelial cells, the intensity of the signal was enhanced in the ventral neuroepithelium (data not shown). Later, at E6/E7, a domain of strong expression was evidenced in the ventral-most region of the neuroepithelium, indicating that Shh signaling is maintained at high level and/or strengthened in this domain (Fig. 4I).

These results reveal a clear temporal change in the distribution of Shh, which becomes concentrated at the surface of the ventralmost Nkx2.2+ neuroepithelial cells before their switch to an OL fate. This local accumulation of Shh is correlated with the establishment or maintenance of a high level of ptc expression in this domain.

\section{Sulfatase 1 acts as a modulator of Shh signaling in the neuroepithelium}

We then investigated the mechanism that could provide Shh accumulation on ventral neural progenitors. We have shown previously that the sulf1 gene, encoding a HSPG-modifying enzyme (Dhoot et al., 2001; Morimoto-Tomita et al., 2002; Ohto et al., 2002; Ai et al., 2003), starts to be expressed in Nkx2.2+ ventral neural progenitors just before OLP specification (BraquartVarnier et al., 2004). HSPGs are extracellular matrix components that play major roles in regulating the distribution and activity of various secreted factors, including Shh (Cardin and Weintraub, 1989; Nybakken and Perrimon, 2002; Rubin et al., 2002; Lin, 2004). Sulf1 thus appeared to be a good candidate to participate in the temporal regulation of the distribution of Shh that leads to accumulation of the protein at the surface of Nkx2.2+ progenitors. Sulf1 expression in the ventral neuroepithelium starts from E4.5/E5 (Fig. $5 A, B$ ) (i.e., $1 \mathrm{~d}$ before $\mathrm{O} 4$ expression), thus precisely foreshadowing the ventral OL domain (Braquart-Varnier et al., 2004). Moreover, its spatiotemporal pattern of expression is well correlated with formation of Shh aggregates at the surface of $\mathrm{Nkx} 2.2+$ progenitors (Figs. $4 D, 5 B$ ). We then asked whether HSPGs, the substrates of Sulf1 enzymatic activity, are expressed in the ventral neuroepithelium. We examined the pattern of expression of the glycosyltransferase exostosin 1 (ext1) transcript during spinal cord development. Ext1 in vertebrates and tout velu $(t t v)$, its ortholog in Drosophila, are involved in the synthesis of HSPGs that regulate the range of activity of Hedgehog family members (Bellaiche et al., 1998; The et al., 1999; Lin and Perrimon, 2000; Koziel et al., 2004). At E3, ext1 was found to be expressed through the entire dorsoventral axis of the neuroepithe-
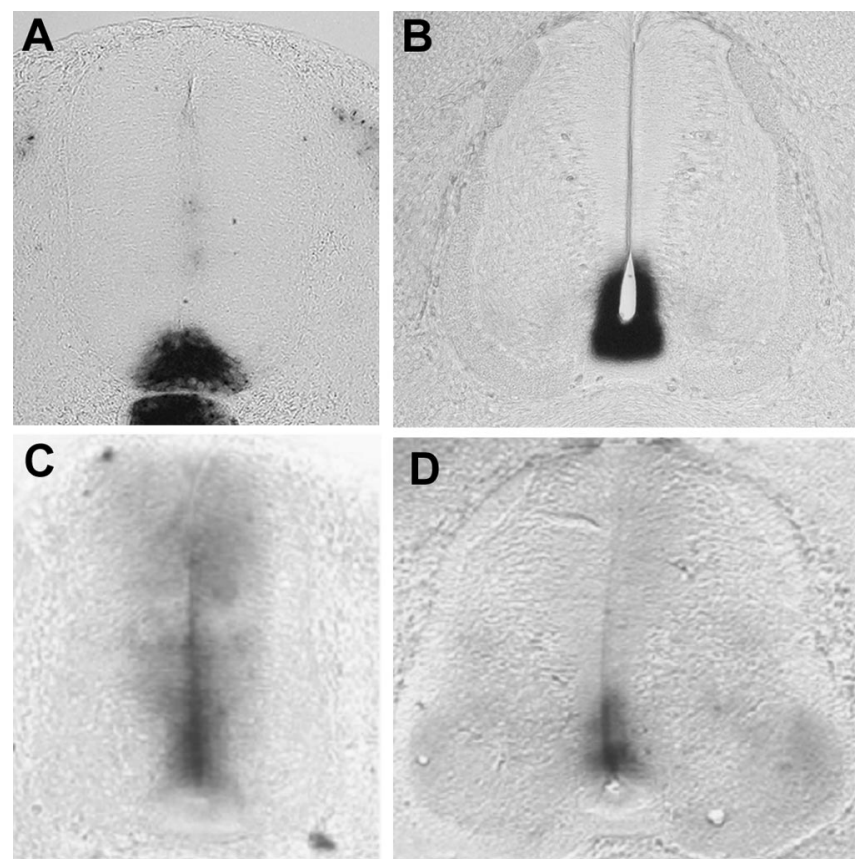

Figure 5. Patterns of expression of sulf1 and ext1 during spinal cord development. Transverse sections of $\mathrm{E} 3(\boldsymbol{A}, \boldsymbol{C}), \mathrm{E} 5(\boldsymbol{B})$, and $\mathrm{E} 6(\boldsymbol{D})$ embryos were stained by in situ hybridization with sulf1 $(\boldsymbol{A}, \boldsymbol{B})$ and ext7 $(\boldsymbol{C}, \boldsymbol{D})$ riboprobes. At $E 3$, sulf1 expression is not detected in ventral neuroepithelial cells and is restricted to floor plate cells $(\boldsymbol{A})$. At E5, the ventral-most neuroepithelial cells have acquired sulf1 expression $(\boldsymbol{B})$. At $\mathrm{E3}$, a decreasing ventrodorsal gradient of expression of ext1 is detected all along the dorsoventral axis of the neuroepithelium (C). At E6, the ext1 domain of expression is restricted to the ventral aspect of the neuroepithelium (D).

lium with a reinforcement of the signal in the ventral region (Fig. $5 C)$. From E5, ext1 was no longer detected in the dorsal neuroepithelium and only faintly expressed by intermediate neural precursors, but its expression remained strong in the ventral-most domain, adjacent to the floor plate (Fig. 5D). This ventral restriction of ext 1 expression was maintained during the period of $\mathrm{OL}$ genesis (data not shown). These data indicate that HSPG synthesis is specifically maintained in the ventral neuroepithelium and provide circumstantial evidence that these molecules may have an important role in regulating the range of Shh activity in the ventral neuroepithelium.

To assess whether Sulf1 does regulate Shh distribution in the neural tube, we analyzed the consequence of sulf1 overexpression on Shh localization at the surface of neural progenitors. These experiments were performed by electroporating an expression vector carrying quail sulf1 cDNA in E4 spinal cords (Ai et al., 2003). Flat-mount explants were then plated in culture, and the distribution of Shh at the surface of neuroepithelial cells was assessed $2 \mathrm{~d}$ later by immunodetection on living tissue, using the $5 \mathrm{E} 1$ antibody as described above. In control explants, electroporated with a green fluorescent protein (GFP)-expressing vector, Shh distribution was unchanged compared with nonelectroporated explants: an intense, punctate staining was detected in the medial region of the explant bordered by a symmetric, weaker staining decreasing dorsally in the ventral neuroepithelium (Fig. $6 B, D)$ (data not shown). In marked contrast, electroporation of the sulf1-expressing vector dramatically modified Shh distribution in the vicinity of electroporated cells by extending dorsally the domain of strong Shh staining (Fig. 6C,D). Confocal analysis clearly showed that Shh accumulated at the surface of sulf1overexpressing cells (Fig. 6C, inset). This modification in Shh localization was not attributable to induction of Shh in neuroep- 

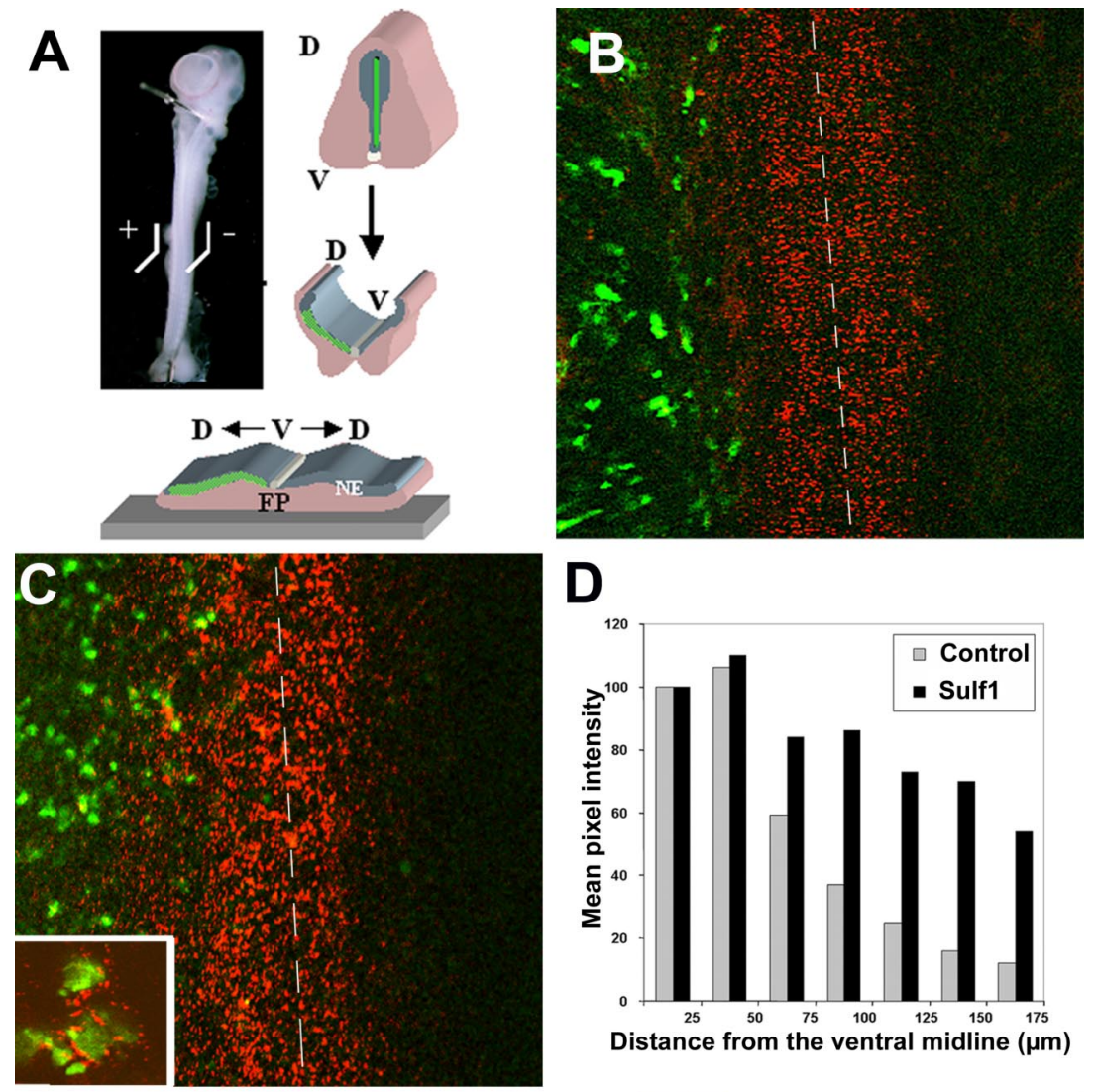

Distance from the ventral midline $(\mu \mathrm{m})$
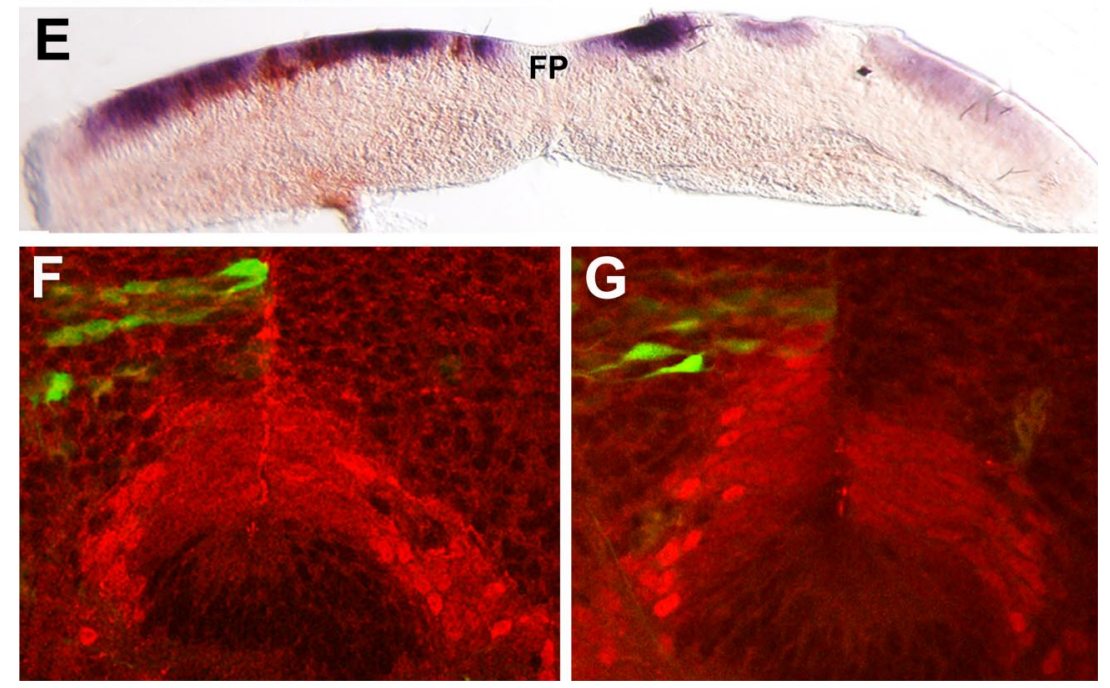

Figure 6. Sulf1 modifies the distribution of Shh at the surface of neural progenitors of the neuroepithelium and activates Shh signaling pathway in this tissue. $\boldsymbol{A}-\boldsymbol{E}$, Electroporation of Sulf1 and/or GFP-expressing vectors were performed in E4 embryonic spinal cord that was further dissected, opened at its dorsal aspect, and plated in culture with the neuroepithelial precursors up (A). The electroporated side is represented on the left in all pictures. The distribution of the Shh protein at the surface of neural progenitors was assessed $2 \mathrm{~d}$ later by immunodetection on living tissue using the $5 E 1$ antibody $(\boldsymbol{B}, \boldsymbol{C})$. Electroporation of a control vector expressing GFP (green) does not modify the distribution of Shh, detected as a decreasing ventrodorsal gradient, compared with the control side (B). In marked contrast, coelectroporation with a Sulf1-expressing vector dramatically changes the pattern of Shh by extending the domain of Shh staining (C). The inset in $($ shows high magnification of Sulf1 electroporated cells that have concentrated Shh at their surface. The dashed lines $(\boldsymbol{B}, \boldsymbol{C})$ highlight the ventral midline of the floor plate. $\boldsymbol{D}$, Quantification of staining intensity showing that the decreasing gradient of Shh observed in control explants is modified by Sulf1 overexpression, which leads to concentration of Shh at distance from the midline. $\boldsymbol{E}$, The readout of Shh signaling was assessed by analyzing $p t c$ expression on transverse section of electroporated explant after $2 \mathrm{~d}$ in culture. Double in situ hybridization experiments show strong induction of ptc (purple) through the entire dorsoventral axis of the neuroepithelium in the vicinity of sulf1-overexpressing neuroepithelial cells (brown). $\boldsymbol{F}, \mathbf{G}$, Control and Sulf1-expressing vectors (green) has been electroporated in E1.5 neural tube, and $\mathrm{Nkx2.2}$ pattern of expression (red) was analyzed at E4.5. High magnification of ventral neuroepithelium showing that overexpression of a control vector does not modify the dorsoventral extension of the Nkx2.2-expressing domain $(\boldsymbol{F})$, whereas this domain extends dorsally in Sulf1-overexpressing spinal cord (G). FP, Floor plate; V, ventral; D, dorsal; NE, neuroepithelium. ithelial cells, because ectopic expression of Shh mRNA was never observed in these experiments (data not shown). These data show that Sulf1 regulates Shh distribution by concentrating the protein at the apical surface of neural progenitors.

To determine whether the modification of Shh distribution induced by sulf1 overexpression resulted in functional activation of Shh signaling, we examined the expression of ptc. The Sulf1-expressing vector was electroporated at E4, and ptc expression was analyzed by in situ hybridization on transverse sections of spinal cord explants $2 \mathrm{~d}$ later. We observed a strong induction of $p t c$ expression in the entire neuroepithelium on the electroporated side, whereas, on the control side, $p t c$ expression was mainly detected in a ventral domain, close to the floor plate, and only faintly in more dorsal regions (Fig. $6 E)$.

To assess the consequences of sulf1 overexpression in the early neural tube, we overexpressed sulf1 in ovo, at E1.5, and analyzed Nkx2.2 expression at E4.5. Whereas overexpression of a control GFPexpressing vector had no effect on $\mathrm{Nkx} 2.2$ pattern of expression (Fig. 6 F), sulf1 overexpression invariably induced dorsal extension of the Nkx2.2-expressing domain (Fig. 6G). Analysis of O4 expression in these embryos showed that overexpressing sulf1 did not induce ectopic and/or premature emergence of O4+ OLPs (data not shown).

All of these results show that overexpression of sulf1 positively regulates Shh signaling and modulates the range of Shh activity in the ventral neuroepithelium. However, misexpression of Sulf1 is not sufficient to induce ectopic OLP specification.

\section{Discussion}

Nkx2.2+ progenitors switch from neuronal to oligodendroglial fate both in $\mathrm{p}^{\star}$ and $\mathrm{p} 3$ domains of the ventral neuroepithelium

A predominant model of fate specification for the spinal cord is that progenitor domains first produce a particular type of neuron and then either OLs or astrocytes. The finding that all $\mathrm{Nkx} 2.2$-expressing progenitors, including those of the $\mathrm{p} 3$ domain, stop to generate neurons when they start to generate O4+ OLPs identifies an additional site in the spinal cord where progenitors make neurons and OLs in a reproducible temporal order and bring new support to the view that the mechanism of the neuronal/glial switch is a general feature in neural development. In the 
pMN domain, this switch is attributable to a temporal shift of gene expression patterns that provides Olig2 with successive regulatory partners, first Ngn1/2 and Pax6, and then Nkx2.2 in the newly formed $\mathrm{p}^{\star}$ domain (Mizuguchi et al., 2001; Novitch et al., 2001; Zhou et al., 2001). Our present results raise the question of molecular mechanisms underlying this change in the $\mathrm{p} 3$ domain. The delayed and reduced expression of OL markers in mice lacking the bHLH (basic helix-loop-helix) transcription factor Ngn3, expressed in $\mathrm{p} 3$ domain at the time of gliogenesis, suggests that this factor may contribute to this process (Lee et al., 2003). The existence of distinct molecular mechanisms involved in specification of the various OLP lineages is supported by the recent identification of additional sources of OLPs arising later from progenitors of the dorsal neuroepithelium (Cai et al., 2005; Fogarty et al., 2005; Vallstedt et al., 2005).

\section{A temporal increase of Shh activity is responsible for the switch from neuronal to oligodendroglial fate in the Nkx2.2 domain}

Prolonged Shh signaling has been shown previously to be required for induction of ventral OLPs at late stages of spinal cord development (Orentas et al., 1999; Soula et al., 2001; Agius et al., 2004; Park et al., 2004). In the present work, we show that strengthening Shh signaling in the neural tube is sufficient to trigger earlier emergence of ventral OLPs and concomitantly inhibit neuronal genesis from ventral progenitors. The absence of floor plate cell induction when Shh was overexpressed in vivo (our present data) (Patten and Placzek, 2002) indicates that premature OLP induction does not result from the activity of other factors produced by floor plate cells but is attributable to a direct effect of Shh on neural progenitors. Thus, our results show that the level of Shh signaling is critical for the proper temporal emergence of OLPs, these cells being specified at higher concentration thresholds of Shh than neurons as reported previously (Soula et al., 2001). Then, apart from its early function in patterning the early neural tube along the dorsoventral axis, Shh plays a major role in regulating the timing of OLP specification in a dosedependent manner. The sudden concentration of Shh that we observed at the apical surface of Nkx2.2-expressing cells at E5, just before OLP specification during normal development, provides strong evidence that ventral neural progenitors of the OL domain are indeed subjected to higher levels of Shh signaling before they switch toward an OL fate. In addition, the subsequent upregulation of the Shh-responsive genes Nkx2.2 and the maintenance of high level of $p t c$ expression in the ventral neuroepithelium strongly support this conclusion.

In our experiments, a rise in Shh concentration invariably induced dorsal extension of both the Nkx2.2 and Olig2 domains and concomitant dorsal shift of the ventral limit of ngn2expressing domain in the ventral neuroepithelium. These results suggest that premature OLP specification observed in Shhoverexpressing experiments may be attributable to premature formation of a $\mathrm{p}^{*}$ domain characterized by the Olig2+/Ngn2-/ $\mathrm{Nkx} 2.2+$ combination known to endow neural progenitors with an OLP identity (Zhou et al., 2001). Our experiments do not allow us to directly assess the contribution Nkx2.2+/Olig2progenitors of the $\mathrm{p} 3$ domain to the early-specified OLPs, because of the lack of a specific marker for this subpopulation of OL cells. Nevertheless, we favor the idea that raising the levels of Shh induces a switch of these progenitors as well, because prematurely induced $\mathrm{O} 4+$ cells were detected in the ventral-most region of the neuroepithelium, adjacent to the floor plate, where Olig2 was never induced and neuronal markers were inhibited.
Our results do not exclude the possibility that a change in the competence of ventral neuroepithelial cells as they integrate the signal could contribute to the dual function of Shh as reported in the mammalian telencephalon (Kohtz et al., 1998). Our present data show that ventral neural progenitors are already competent to generate OL cells during the period of neuronal genesis if they perceive the appropriate dose of Shh. In contrast, we never induced OL markers in the dorsal neuroepithelium even when Shhoverexpressing cells were located in the dorsal aspect of the neural tube, suggesting that these cells are not competent to generate ventral OLP in response to Shh. However, we know from previous experiments that notochord is able to induce ventral OLPs from dorsal progenitors (Trousse et al., 1995; Orentas and Miller, 1996; Poncet et al., 1996; Pringle et al., 1996). This discrepancy may be explained by the production of other factors by notochord cells that may contribute to acquisition of a competence. Another major difference between these experiments and our present data resides in the duration of exposure of dorsal progenitors to Shh signaling. Two critical periods of Shh signaling are required to induce $\mathrm{MNs}$, an early period during which naive neural plate cells are converted into ventralized progenitors and a late phase during which Shh drives their differentiation into MNs (Ericson et al., 1996). This raises the possibility that not only the strength but also the duration of Shh signaling influences the fate choice of neural progenitors, as recently proposed in neural tube and limb development (Ahn and Joyner, 2004; Harfe et al., 2004; Park et al., 2004; Stamataki et al., 2005). Alternatively, the absence of premature induction of OLPs in the dorsal spinal cord may be explained by the repressive activity of bone morphogenetic protein (BMP) on OLP specification (Mekki-Dauriac et al., 2002).

\section{Sulf1 acts as a modulator of Shh signaling in the ventral neuroepithelium}

In the embryonic chicken spinal cord, Sulf1 starts to be expressed in Nkx2.2-expressing progenitors concomitantly to Shh accumulation at their surface (our present data) (Braquart-Varnier et al., 2004). Our results showing that misexpression of sulf1 in neural progenitors modifies the distribution of Shh, which become concentrated at the apical surface of these cells and leads to upregulation of $p t c$ and $\mathrm{Nkx} 2.2$ expression, provide evidence that Sulf1 acts as a positive regulator of Shh signaling in the ventral neuroepithelium. Sulf1 belongs to a family of membrane-associated sulfatases, comprising two members, Sulf1 and Sulf2, whose function is to modulate the sulfation state of HSPGs by removing sulfate (Dhoot et al., 2001; Ohto et al., 2002; Morimoto-Tomita et al., 2002; Ai et al., 2003; Kakinuma et al., 2004; Viviano et al., 2004). HSPGs are now considered to be crucial players in numerous signaling pathways during development and Sulf1 by its catalytic activity on HSPGs has been shown to act as a regulator of FGF, Wnt, and BMP signaling in different cellular contexts (Dhoot et al., 2001; Esko and Selleck, 2002; Ai et al., 2003; Lin, 2004; Viviano et al., 2004; Wang et al., 2004). Our results now involve Sulf1 in the regulation of Shh signaling and raise the question of how Sulf1 may modulate the response to Shh in neural progenitors. It is now clearly established that Shh, by its Cardin-Weintraub sequence, interacts with sulfates contained within the glycosaminoglycan side chains of proteoglycans (Cardin and Weintraub, 1989; Rubin et al., 2002) and that Hh family members require HSPGs for their proper distribution and signaling both in Drosophila and vertebrates (Bellaiche et al., 1998; The et al.; 1999, Rubin et al., 2002; Koziel et al., 2004). Our data showing the temporally appropriate expression of ext1 in the ventral neuroepithelium indicate that Sulf1 substrates are synthe- 
sized locally. Strikingly, the accumulation of Shh at the surface of neural progenitors, either during normal development or after sulf1 overexpression, is visualized as a punctate staining very reminiscent of the large punctate structures (LPSs) described in Drosophila (Gallet et al., 2003; Gallet and Therond, 2005). These structures are involved in the activation of specific target genes in epithelial cells of the epidermis, and $t t v$, a fly member of ext genes, is required for the transport and/or stability of LPS in the Hedgehog receiving tissue (Bellaiche et al., 1998; The et al., 1999). As a parallel, our data suggest that a temporal variation of HSPG pattern, triggered by Sulf1, is likely to occur in the ventral neuroepithelium and that this, in turn, induces a local change of Shh concentration by regulating its transport and/or stability. However, despite its activity on Shh signaling, Sulf1 misexpressed in the early neural tube is not sufficient to mimic the effect of Shh overexpression by inducing O4+ OLP premature and/or ectopic specification. This may reflect a lower level of Shh signaling activation in sulf1 overexpression experiments as assessed by the less efficient dorsal induction of Nkx2.2 (Figs. 3G, 6H). Additionally, the absence of OLP induction may reflect the persistence of BMP repressing activity in these experiments.

In summary, our results show a temporal change in Shh distribution and activity in the ventral neuroepithelium just before the N/OL switch. We propose the following model (see supplemental figure, available at www.jneurosci.org as supplemental material), in which neural progenitors of the early ventral neural tube generate neurons in response to a defined level of Shh according to their dorsoventral position (Briscoe et al., 2000; Jessell, 2000). Then, from E5 in chick embryo, a higher level of Shh signaling in the ventral neuroepithelium target field is further translated by expression of genes that specify OL fate at the expense of neuronal fate. We propose that Sulf1 contributes to activation of Shh signaling by the formation of Shh/HSPGs complexes at the surface of receiving cells, as a consequence of its desulfation of HSPGs, thereby concentrating it and/or facilitating presentation to its receptor.

\section{References}

Agius E, Soukkarieh C, Danesin C, Kan P, Takebayashi H, Soula C, Cochard P (2004) Converse control of oligodendrocyte and astrocyte lineage development by Sonic hedgehog in the chick spinal cord. Dev Biol 270:308-321.

Ahn S, Joyner AL (2004) Dynamic changes in the response of cells to positive hedgehog signaling during mouse limb patterning. Cell 118:505-516.

Ai X, Do AT, Lozynska O, Kusche-Gullberg M, Lindahl U, Emerson Jr CP (2003) QSulf1 remodels the 6-O sulfation states of cell surface heparan sulfate proteoglycans to promote Wnt signaling. J Cell Biol 162:341-351.

Bansal R, Warrington AE, Gard AL, Ranscht B, Pfeiffer SE (1989) Multiple and novel specificities of monoclonal antibodies $\mathrm{O} 1, \mathrm{O} 4$, and $\mathrm{R}-\mathrm{mAb}$ used in the analysis of oligodendrocyte development. J Neurosci Res 24:548-557.

Bellaiche Y, The I, Perrimon N (1998) Tout-velu is a Drosophila homologue of the putative tumour suppressor EXT-1 and is needed for Hh diffusion. Nature 394:85-88.

Braquart-Varnier C, Danesin C, Clouscard-Martinato C, Agius E, Escalas N, Benazeraf B, Ai X, Emerson C, Cochard P, Soula C (2004) A subtractive approach to characterize genes with regionalized expression in the gliogenic ventral neuroepithelium: identification of chick sulfatase 1 as a new oligodendrocyte lineage gene. Mol Cell Neurosci 25:612-628.

Briscoe J, Ericson J (2001) Specification of neuronal fates in the ventral neural tube. Curr Opin Neurobiol 11:43-49.

Briscoe J, Sussel L, Serup P, Hartigan-O'Connor D, Jessell TM, Rubenstein JL, Ericson J (1999) Homeobox gene Nkx2.2 and specification of neuronal identity by graded Sonic hedgehog signalling. Nature 398:622-627.

Briscoe J, Pierani A, Jessell TM, Ericson J (2000) A homeodomain protein code specifies progenitor cell identity and neuronal fate in the ventral neural tube. Cell 101:435-445.
Cai J, Qi Y, Hu X, Tan M, Liu Z, Zhang J, Li Q, Sander M, Qiu M (2005) Generation of oligodendrocyte precursor cells from mouse dorsal spinal cord independent of Nkx6 regulation and Shh signaling. Neuron 45:41-53.

Cardin AD, Weintraub HJ (1989) Molecular modeling of proteinglycosaminoglycan interactions. Arteriosclerosis 9:21-32.

Dhoot GK, Gustafsson MK, Ai X, Sun W, Standiford DM, Emerson CP Jr (2001) Regulation of Wnt signaling and embryo patterning by an extracellular sulfatase. Science 293:1663-1666.

Dubois L, Bally-Cuif L, Crozatier M, Moreau J, Paquereau L, Vincent A (1998) XCoe2, a transcription factor of the Col/Olf-1/EBF family involved in the specification of primary neurons in Xenopus. Curr Biol 8:199-209.

Ericson J, Morton S, Kawakami A, Roelink H, Jessell TM (1996) Two critical periods of Sonic Hedgehog signaling required for the specification of motor neuron identity. Cell 87:661-673.

Esko JD, Selleck SB (2002) Order out of chaos: assembly of ligand binding sites in heparan sulfate. Annu Rev Biochem 71:435-471.

Fan CM, Kuwana E, Bulfone A, Fletcher CF, Copeland NG, Jenkins NA, Crews S, Martinez S, Puelles L, Rubenstein JL, Tessier-Lavigne M (1996) Expression patterns of two murine homologs of Drosophila single-minded suggest possible roles in embryonic patterning and in the pathogenesis of Down syndrome. Mol Cell Neurosci [Erratum (1996) 7:519] 7:1-16.

Fogarty M, Richardson WD, Kessaris N (2005) A subset of oligodendrocytes generated from radial glia in the dorsal spinal cord. Development 132:1951-1959.

Fu H, Qi Y, Tan M, Cai J, Takebayashi H, Nakafuku M, Richardson W, Qiu M (2002) Dual origin of spinal oligodendrocyte progenitors and evidence for the cooperative role of Olig2 and Nkx2.2 in the control of oligodendrocyte differentiation. Development 129:681-693.

Gallet A, Therond PP (2005) Temporal modulation of the Hedgehog morphogen gradient by a patched-dependent targeting to lysosomal compartment. Dev Biol 277:51-62.

Gallet A, Rodriguez R, Ruel L, Therond PP (2003) Cholesterol modification of hedgehog is required for trafficking and movement, revealing an asymmetric cellular response to hedgehog. Dev Cell 4:191-204.

Garel S, Marin F, Mattei MG, Vesque C, Vincent A, Charnay P (1997) Family of Ebf/Olf-1-related genes potentially involved in neuronal differentiation and regional specification in the central nervous system. Dev Dyn 210:191-205.

Goodrich LV, Johnson RL, Milenkovic L, McMahon JA, Scott MP (1996) Conservation of the hedgehog/patched signaling pathway from flies to mice: induction of a mouse patched gene by Hedgehog. Genes Dev 10:301-312.

Gritli-Linde A, Lewis P, McMahon AP, Linde A (2001) The whereabouts of a morphogen: direct evidence for short- and graded long-range activity of hedgehog signaling peptides. Dev Biol 236:364-386.

Hamburger V, Hamilton HL (1992) A series of normal stages in the development of the chick embryo. 1951 [classical article]. Dev Dyn 195:231-272.

Harfe BD, Scherz PJ, Nissim S, Tian H, McMahon AP, Tabin CJ (2004) Evidence for an expansion-based temporal Shh gradient in specifying vertebrate digit identities. Cell 118:517-528.

Itasaki N, Bel-Vialar S, Krumlauf R (1999) "Shocking" developments in chick embryology: electroporation and in ovo gene expression. Nat Cell Biol 1:E203-E207.

Jessell TM (2000) Neuronal specification in the spinal cord: inductive signals and transcriptional codes. Nat Rev Genet 1:20-29.

Kakinuma Y, Saito F, Ohsawa S, Furuichi T, Miura M (2004) A sulfatase regulating the migratory potency of oligodendrocyte progenitor cells through tyrosine phosphorylation of beta-catenin. J Neurosci Res 77:653-661.

Kessaris N, Pringle N, Richardson WD (2001) Ventral neurogenesis and the neuron-glial switch. Neuron 31:677-680.

Kohtz JD, Baker DP, Corte G, Fishell G (1998) Regionalization within the mammalian telencephalon is mediated by changes in responsiveness to Sonic Hedgehog. Development 125:5079-5089.

Koziel L, Kunath M, Kelly OG, Vortkamp A (2004) Ext1-dependent heparan sulfate regulates the range of Ihh signaling during endochondral ossification. Dev Cell 6:801-813.

Lee J, Wu Y, Qi Y, Xue H, Ying Liu Y, Scheel D, German M, Qiu M, Guillemot 
F, Rao M (2003) Neurogenin3 participates in gliogenesis in the developing vertebrate spinal cord. Dev Biol 253:84-98.

Lin X (2004) Functions of heparan sulfate proteoglycans in cell signaling during development. Development 131:6009-6021.

Lin X, Perrimon N (2000) Role of heparan sulfate proteoglycans in cell-cell signaling in Drosophila. Matrix Biol 19:303-307.

Lu QR, Yuk D, Alberta JA, Zhu Z, Pawlitzky I, Chan J, McMahon AP, Stiles CD, Rowitch DH (2000) Sonic hedgehog-regulated oligodendrocyte lineage genes encoding $\mathrm{bHLH}$ proteins in the mammalian central nervous system. Neuron 25:317-329.

Lu QR, Sun T, Zhu Z, Ma N, Garcia M, Stiles CD, Rowitch DH (2002) Common developmental requirement for Olig function indicates a motor neuron/oligodendrocyte connection. Cell 109:75-86.

Marigo V, Tabin CJ (1996) Regulation of patched by sonic hedgehog in the developing neural tube. Proc Natl Acad Sci USA 93:9346-9351.

Marquardt T, Pfaff SL (2001) Cracking the transcriptional code for cell specification in the neural tube. Cell 106:651-654.

Mekki-Dauriac S, Agius E, Kan P, Cochard P (2002) Bone morphogenetic proteins negatively control oligodendrocyte precursor specification in the chick spinal cord. Development 129:5117-5130.

Miller RH (2002) Regulation of oligodendrocyte development in the vertebrate CNS. Prog Neurobiol 67:451-467.

Miller RH, Payne J, Milner L, Zhang H, Orentas DM (1997) Spinal cord oligodendrocytes develop from a limited number of migratory highly proliferative precursors. J Neurosci Res 50:157-168.

Mizuguchi R, Sugimori M, Takebayashi H, Kosako H, Nagao M, Yoshida S, Nabeshima Y, Shimamura K, Nakafuku M (2001) Combinatorial roles of olig2 and neurogenin2 in the coordinated induction of pan-neuronal and subtype-specific properties of motoneurons. Neuron 31:757-771.

Morimoto-Tomita M, Uchimura K, Werb Z, Hemmerich S, Rosen SD (2002) Cloning and characterization of two extracellular heparindegrading endosulfatases in mice and humans. J Biol Chem 277:49175-49185.

Novitch BG, Chen AI, Jessell TM (2001) Coordinate regulation of motor neuron subtype identity and pan-neuronal properties by the bHLH repressor Olig2. Neuron 31:773-789.

Nybakken K, Perrimon N (2002) Heparan sulfate proteoglycan modulation of developmental signaling in Drosophila. Biochim Biophys Acta 1573:280-291.

Ohto T, Uchida H, Yamazaki H, Keino-Masu K, Matsui A, Masu M (2002) Identification of a novel nonlysosomal sulphatase expressed in the floor plate, choroid plexus and cartilage. Genes Cells 7:173-185.

Ono K, Bansal R, Payne J, Rutishauser U, Miller RH (1995) Early development and dispersal of oligodendrocyte precursors in the embryonic chick spinal cord. Development 121:1743-1754.

Orentas DM, Miller RH (1996) The origin of spinal cord oligodendrocytes is dependent on local influences from the notochord. Dev Biol 177:43-53.

Orentas DM, Hayes JE, Dyer KL, Miller RH (1999) Sonic hedgehog signaling is required during the appearance of spinal cord oligodendrocyte precursors. Development 126:2419-2429.

Park HC, Shin J, Appel B (2004) Spatial and temporal regulation of ventral spinal cord precursor specification by Hedgehog signaling. Development 131:5959-5969.

Patten I, Placzek M (2002) Opponent activities of Shh and BMP signaling during floor plate induction in vivo. Curr Biol 12:47-52.

Poncet C, Soula C, Trousse F, Kan P, Hirsinger E, Pourquie O, Duprat AM, Cochard P (1996) Induction of oligodendrocyte progenitors in the trunk neural tube by ventralizing signals: effects of notochord and floor plate grafts, and of sonic hedgehog. Mech Dev 60:13-32.

Pourquié O, Fan CM, Coltey M, Hirsinger E, Watanabe Y, Breant C, FrancisWest P, Brickell P, Tessier-Lavigne M, Le Douarin NM (1996) Lateral and axial signals involved in avian somite patterning: a role for BMP4. Cell 84:461-471.

Pringle NP, Yu WP, Guthrie S, Roelink H, Lumsden A, Peterson AC, Richardson WD (1996) Determination of neuroepithelial cell fate: induction of the oligodendrocyte lineage by ventral midline cells and sonic hedgehog. Dev Biol 177:30-42.

Richardson WD, Smith HK, Sun T, Pringle NP, Hall A, Woodruff R (2000) Oligodendrocyte lineage and the motor neuron connection. Glia 29:136-142.

Riddle RD, Johnson RL, Laufer E, Tabin C (1993) Sonic hedgehog mediates the polarizing activity of the ZPA. Cell 75:1401-1416.

Rowitch DH (2004) Glial specification in the vertebrate neural tube. Nat Rev Neurosci 5:409-419.

Rowitch DH, Lu QR, Kessaris N, Richardson WD (2002) An "oligarchy" rules neural development. Trends Neurosci 25:417-422.

Roztocil T, Matter-Sadzinski L, Alliod C, Ballivet M, Matter JM (1997) NeuroM, a neural helix-loop-helix transcription factor, defines a new transition stage in neurogenesis. Development 124:3263-3272.

Rubin JB, Choi Y, Segal RA (2002) Cerebellar proteoglycans regulate sonic hedgehog responses during development. Development 129:2223-2232.

Sommer I, Schachner M (1981) Monoclonal antibodies (O1 to O4) to oligodendrocyte cell surfaces: an immunocytological study in the central nervous system. Dev Biol 83:311-327.

Soula C, Danesin C, Kan P, Grob M, Poncet C, Cochard P (2001) Distinct sites of origin of oligodendrocytes and somatic motoneurons in the chick spinal cord: oligodendrocytes arise from $\mathrm{Nkx} 2.2$-expressing progenitors by a Shh-dependent mechanism. Development 128:1369-1379.

Stamataki D, Ulloa F, Tsoni SV, Mynett A, Briscoe J (2005) A gradient of Gli activity mediates graded Sonic Hedgehog signaling in the neural tube. Genes Dev 19:626-641.

Takebayashi H, Yoshida S, Sugimori M, Kosako H, Kominami R, Nakafuku M, Nabeshima Y (2000) Dynamic expression of basic helix-loop-helix Olig family members: implication of Olig2 in neuron and oligodendrocyte differentiation and identification of a new member, Olig3. Mech Dev 99:143-148.

Takebayashi H, Nabeshima Y, Yoshida S, Chisaka O, Ikenaka K (2002) The basic helix-loop-helix factor olig2 is essential for the development of motoneuron and oligodendrocyte lineages. Curr Biol 12:1157-1163.

Tanabe Y, William C, Jessell TM (1998) Specification of motor neuron identity by the MNR2 homeodomain protein. Cell 95:67-80.

The I, Bellaiche Y, Perrimon N (1999) Hedgehog movement is regulated through tout velu-dependent synthesis of a heparan sulfate proteoglycan. Mol Cell 4:633-639.

Trousse F, Giess MC, Soula C, Ghandour S, Duprat AM, Cochard P (1995) Notochord and floor plate stimulate oligodendrocyte differentiation in cultures of the chick dorsal neural tube. J Neurosci Res 41:552-560.

Vallstedt A, Klos JM, Ericson J (2005) Multiple dorsoventral origins of oligodendrocyte generation in the spinal cord and hindbrain. Neuron 45:55-67.

Viviano BL, Paine-Saunders S, Gasiunas N, Gallagher J, Saunders S (2004) Domain-specific modification of heparan sulfate by Qsulf1 modulates the binding of the bone morphogenetic protein antagonist Noggin. J Biol Chem 279:5604-5611.

Wang S, Ai X, Freeman SD, Pownall ME, Lu Q, Kessler DS, Emerson Jr CP (2004) QSulf1, a heparan sulfate 6-O-endosulfatase, inhibits fibroblast growth factor signaling in mesoderm induction and angiogenesis. Proc Natl Acad Sci USA 101:4833-4838.

Xu X, Cai J, Fu H, Wu R, Qi Y, Modderman G, Liu R, Qiu M (2000) Selective expression of Nkx-2.2 transcription factor in chicken oligodendrocyte progenitors and implications for the embryonic origin of oligodendrocytes. Mol Cell Neurosci 16:740-753.

Zhou Q, Anderson DJ (2002) The bHLH transcription factors OLIG2 and OLIG1 couple neuronal and glial subtype specification. Cell 109:61-73.

Zhou Q, Wang S, Anderson DJ (2000) Identification of a novel family of oligodendrocyte lineage-specific basic helix-loop-helix transcription factors. Neuron 25:331-343.

Zhou Q, Choi G, Anderson DJ (2001) The bHLH transcription factor Olig2 promotes oligodendrocyte differentiation in collaboration with $\mathrm{Nkx2.2}$. Neuron 31:791-807. 